\title{
hCLP46 increases Smad3 protein stability via inhibiting its ubiquitin-proteasomal degradation
}

\section{Dear Editor,}

hCLP46 (human CAP10-like protein $46 \mathrm{kDa}$ ) was initially isolated and identified from human acute myeloid leukemia transformed from myelodysplastic syndrome (MDS-AML) $\mathrm{CD}^{+} 4^{+}$cells (Teng et al., 2006) and we demonstrated previously that hCLP46 is abnormally expressed in many hematopoietic malignancies (Wang et al., 2010). Studies from its Drosophila homolog, Rumi, suggested that Notch is a potential target of hCLP46 (Acar et al., 2008). We also found that overexpression of hCLP46 enhances Notch activation and regulates cell proliferation in a cell type-dependent manner (Ma et al., 2011; Chu et al., 2013). However, hCLP46 ${ }^{-/-}$ embryos show more severe phenotypes compared to those displayed by other global regulators of canonical Notch signaling, suggesting that hCLP46 is likely to have additional important targets during mammalian development (Fernandez-Valdivia et al., 2011). Based on the crosstalk between Notch and the transforming growth factor- $\beta$ (TGF- $\beta$ ) signaling, we proposed that hCLP46 might be involved in TGF- $\beta$ signal regulation, but the detail mechanism remains unclear.

With the full length or truncated plasmids encoding hCLP46 1-120 aa (no CAP10 domain) or hCLP46 121-392 aa (with CAP10 domain), we found that overexpression of hCLP46 1-120 aa had no obvious effect on Smad3 expression, whereas both hCLP46 121-392 aa and hCLP46-full length significantly increased Smad3 protein expression, suggesting that hCLP46 increases Smad3 expression in a CAP10 domain dependent manner (Fig. 1A and 1B). To determine the mechanism through which hCLP46 regulates Smad3 expression, we generated a stable cell line inducibly overexpressing hCLP46, which is named as 293TRexhCLP46 hereinafter. When cells were incubated with $0.5 \mu \mathrm{g} / \mathrm{mL}$ Tetracycline (Tet) for $24 \mathrm{~h}$, the pronounced induction of hCLP46 resulted in $85 \%$ increase of Smad3 expression (Fig. 1C and 1D). We then examined Smad3 protein turnover in 293TRex-hCLP46 cells by blocking protein synthesis. In Tet off cells, administration of $\mathrm{CHX}(50 \mu \mathrm{g} / \mathrm{mL})$ caused a remarkable decrease of Smad3 in a time dependent manner (Fig. $1 \mathrm{C}$ and $1 \mathrm{D}$ ). The half-life is only about $0.5 \mathrm{~h}$, suggesting that endogenous Smad3 undergoes fast degradation at the steady state. However, the half-life of Smad3 protein was significantly longer in Tet on cells as compared with that observed in Tet off cells, suggesting that hCLP46 could increase Smad3 protein stability (Fig. 1C and 1D). When endogenous hCLP46 was knocked down by siRNA, significantly reduction in Smad3 expression was observed (Fig. 1E). It is notable that the mRNA levels of Smad3 were not affected by overexpression or knockdown of hCLP46 (Fig. S1A and S1B). To determine whether the degradation of Smad3 is mediated by proteasome, we treated 293TRexhCLP46 cells with $20 \mu \mathrm{mol} / \mathrm{L} 26 \mathrm{~S}$ proteasome inhibitor MG132 for $3 \mathrm{~h}$, which resulted in a two-fold increase in Smad3 expression in Tet off cells (Fig. 1F and 1G). In the presence of MG132, hCLP46 overexpression still significantly increased Smad3 protein level whereas hCLP46 knockdown had no obvious effect on Smad3 expression (Fig. $1 F$ and 1G). Consistently, we found that Smad3 was polyubiquitinated in cells treated with MG132 and the ubiquitination of Smad3 was attenuated by overexpression of hCLP46 (Fig. 1H), but enhanced by knockdown of endogenous hCLP46 (Fig. 1I), suggesting that hCLP46 increases Smad3 expression and protein stability through inhibiting proteasomal degradation of Smad3.

We then attempted to evaluate the impact of hCLP46 on TGF- $\beta$ signaling. Overexpression of hCLP46 inhibited cell viability at basal condition and further exacerbated TGF- $\beta 1$ induced cell viability inhibition ( $2 \mathrm{ng} / \mathrm{mL}, 24 \mathrm{~h})$ (Fig. $2 \mathrm{~A})$. In contrast, knockdown of hCLP46 by siRNA increased cell viability and almost totally blocked the inhibition of cell proliferation by TGF- $\beta 1$ (Fig. 2B). In addition, TGF- $\beta 1$ treatment significantly increased the expression of two cell cycle inhibitors (p21 and p27) as compared to control cells, which were further enhanced by overexpression of hCLP46 (Fig. 2C and 2D), whereas attenuated by knockdown of hCLP46 (Fig. 2E and 2F), suggesting that hCLP46 enhances TGF- $\beta$ signaling by modulating Smad3 expression.

As Notch signaling might be involved in Smad3 regulation, we treated cells with DAPT $(2 \mu \mathrm{mol} / \mathrm{L}, 12 \mathrm{~h})$ or EDTA $(5 \mathrm{mmol} / \mathrm{L}, 15 \mathrm{~min}$ and then replaced with fresh DMEM plus $10 \%$ FBS and cultured for additional $6 \mathrm{~h}$ ) to inhibit or activate 


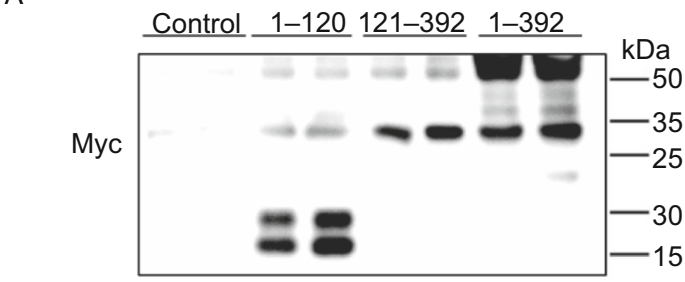

Smad3 $-\cdots \cdots-\cdots$ B-Tubulin
C

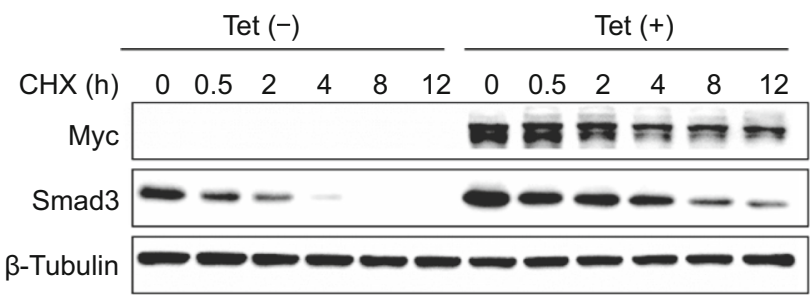

$E$

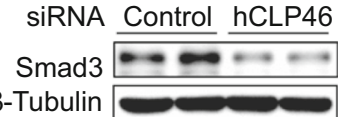

$\mathrm{H}$
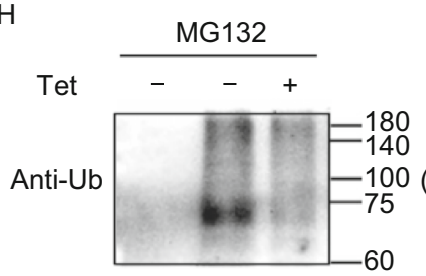

Smad3

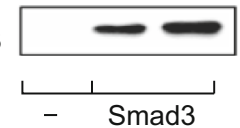

$\mathrm{F}$

MG132 $\beta$-Tubulin

I

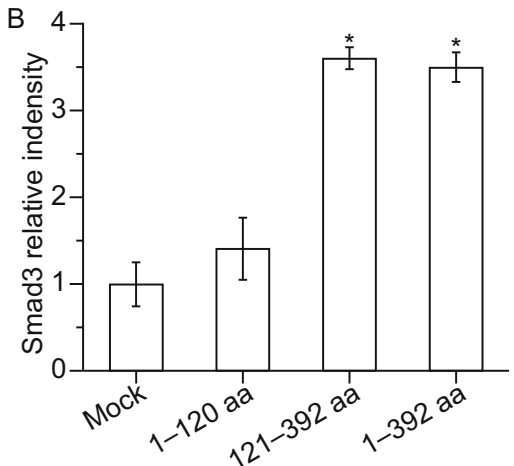

D

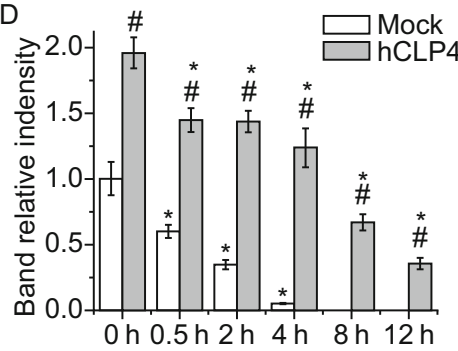

G

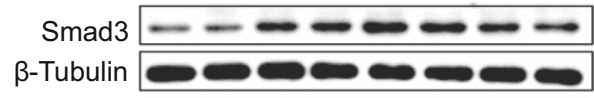

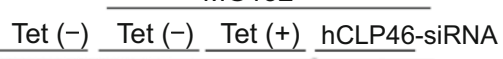
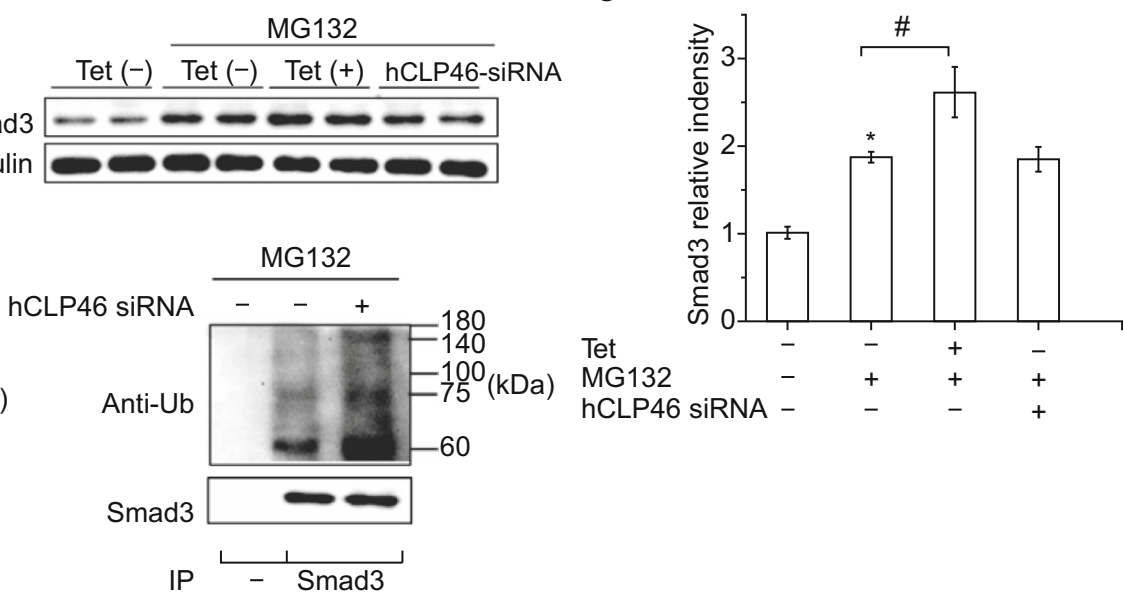

Figure 1. hCLP46 increases Smad3 expression by preventing its proteasomal degradation in 293TRex cells. (A) 293TRex cells were transfected with full length of hCLP46 or truncated plasmids encoding hCLP46 1-120 aa or hCLP46 121-392 aa for 48 h, the protein levels of Myc and Smad3 were determined by Western blot. (C) 293TRex-hCLP46 cells were cultured in absence or presence of $0.5 \mu \mathrm{g} / \mathrm{mL}$ Tet for $24 \mathrm{~h}$ and $50 \mu \mathrm{g} / \mathrm{mL} \mathrm{CHX}$ was then added as indicated. Total cell lysates were probed for Myc and Smad3. (E) After transfected with control or hCLP46 specific siRNA for $72 \mathrm{~h}$, the protein level of Smad3 was determined. (F) 293TRex-hCLP46 cells were incubated with or without $0.5 \mu \mathrm{g} / \mathrm{mL}$ Tet for $24 \mathrm{~h}$ or transfected with hCLP46 specific siRNA for $72 \mathrm{~h}$, $20 \mu \mathrm{mol} / \mathrm{L}$ MG132 was then added for $3 \mathrm{~h}$. Cell lysates were examined by Western blot for Smad3 or used for immunoprecipitation (IP) with no antibody (-) or anti-Smad3 then probed with ubiquitin antibody (anti-Ub) (H and I). $\beta$-Tubulin was used as a loading control in $(A),(C),(E)$ and $(F)$. Immunoblot band intensities were quantified using loading controls (B, D and $G)$. $n=4$ in each group. *Indicates $P<0.05$ comparing to control and hCLP46 plasmids transfected or CHX/MG132 treated cells. ${ }^{\#}$ Indicates $P<0.05$ comparing to control and hCLP46 overexpressed cells.

Notch signaling respectively. DAPT treatment resulted in dramatically decrease of the NICD expression, but has no effect on Smad3 expression (Fig. S2A-C). EDTA significantly increased NICD and Smad3 levels. However, cells with hCLP46 overexpression still had more Smad3 expression than that of control cells (Fig. S2D-F). Together, these data suggest that hCLP46 regulates Smad3 expression is not affected by Notch signaling.

As the primary intracellular transducer, Smad3 is a critical mediator of the cytostatic response to TGF- $\beta$ (Zhang et al., 2014). Evidence for this comes from the observation that a variety of primary cells from Smad3-null mice are partially 
A

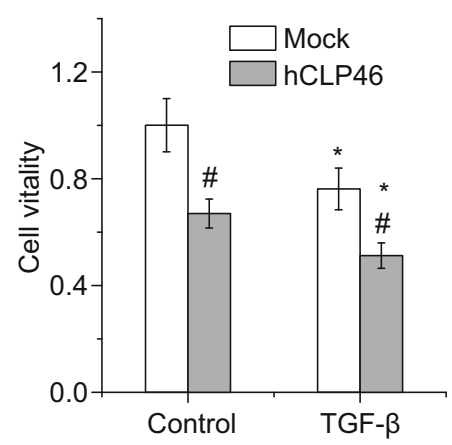

C

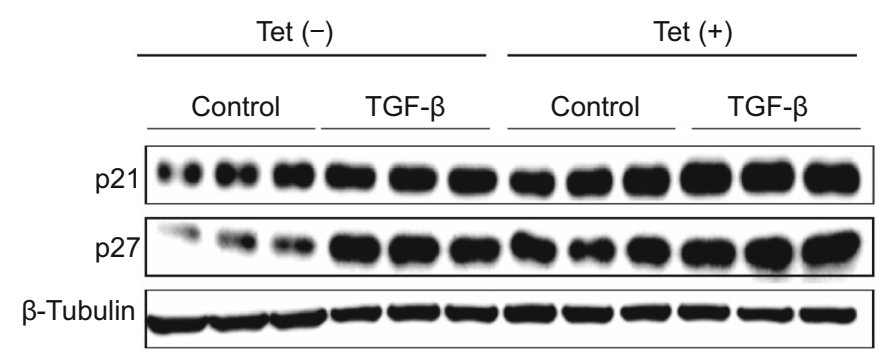

$\mathrm{E}$

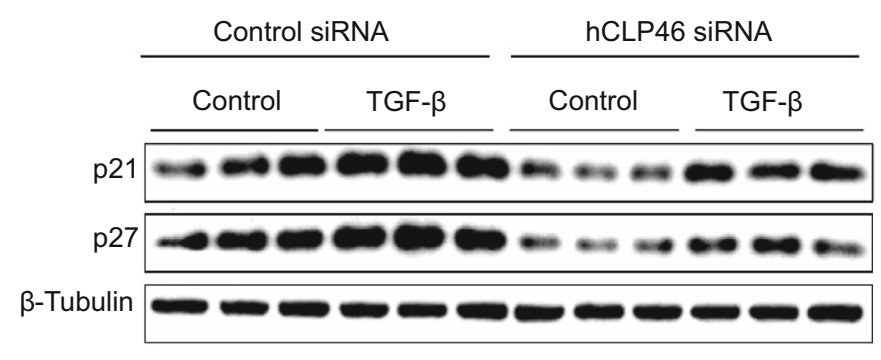

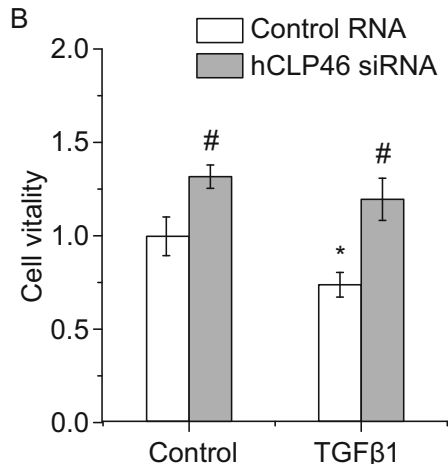

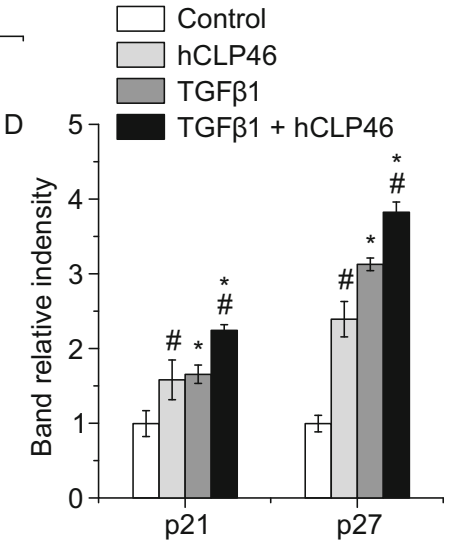

$\mathrm{F}$

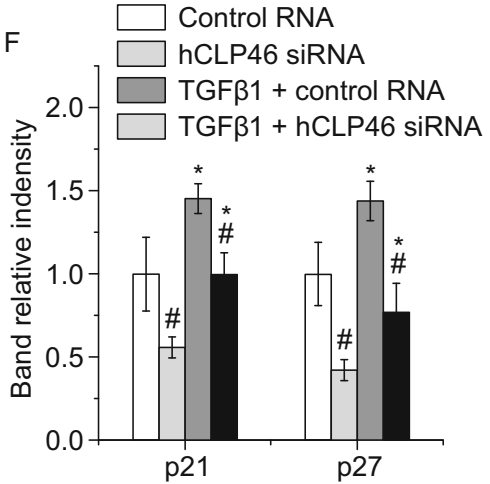

Figure 2. hCLP46 enhanced TGF- $\beta 1$ induced cell growth arrest and up-regulation of cell cycle inhibitors. (A) 293TRexhCLP46 cells were cultured in absence or presence of $0.5 \mu \mathrm{g} / \mathrm{mL}$ Tet for $24 \mathrm{~h}$ and $2 \mathrm{ng} / \mathrm{mL}$ TGF- $\beta 1$ was then added for $24 \mathrm{~h}$. Cell viability was determined by MTT method. (B) 293TRex-hCLP46 cells were maintained in absence of Tet and transfected with control or hCLP46 specific siRNA for $48 \mathrm{~h}$. Then cells were treated with $2 \mathrm{ng} / \mathrm{mL}$ TGF- $\beta 1$ for additional $24 \mathrm{~h}$. Cell viability was determined by MTT method. In (A) and (B), data were collected from 8 independent experiments. (C) Lysates from control, Tet, TGF- $\beta 1$ and Tet plus TGF- $\beta 1$ treated cells were probed for $p 21$ and p27. (E) The protein levels of $p 21$ and $p 27$ were also determined in lysates from control, hCLP46 siRNA, TGF- $\beta 1$ and hCLP46 siRNA plus TGF- $\beta 1$ treated cells. $\beta$-Tubulin was used as a loading control in (C) and (E). Immunoblot band intensities were quantified using loading controls ( $\mathrm{D}$ and $\mathrm{F}$ ). $n=3$ in each group. *Indicates $P<0.05$ comparing to control and TGF- $\beta 1$ treated cells. "Indicates $P<0.05$ comparing to control and hCLP46 overexpressed or hCLP46 siRNA transfected cells.

resistant to TGF- $\beta$ induced growth arrest (Datto et al., 1999; Yang et al., 1999) and exogenous overexpression of Smad3 sensitizes cells to TGF- $\beta$ induced growth arrest and apoptosis (Wildey et al., 2003). Importantly, it was found that treatment with the proteasome inhibitor caused an accumulation of Smad3 protein in absence of TGF- $\beta 1$, suggesting that not only in response to TGF- $\beta$ but also in a steady state, the level of Smad3 is regulated by the proteasome pathway (Inoue et al., 2004). In addition, several studies demonstrated that the steady-state stability of Smad3 is an important determinant of cellular sensitivity to TGF- $\beta$ (Guo et al., 2008) and the U-box-containing carboxyl terminus of Hsc70-interacting protein has been identified as an E3 ubiquitin ligase to degrade Smad3 at steady state (Xin et al., 2005). In agreement with those findings, we demonstrated that hCLP46 modulates Smad3 protein stability by inhibiting 
its proteasomal degradation and consequently enhances cellular sensitivity to the TGF- $\beta$ signal. Our findings suggest a new function of hCLP46 in modulating critical TGF- $\beta$ / Smad3-regulated processes during development and tumor progression.

\section{FOOTNOTES}

This study was supported by grants from National Natural Science Foundation of China (Grant Nos. 30670889, 81270319 and 81470520), Guangdong Innovation Team Project (2013S086), Guandong Natural Science Foundation (2014A030312018), the National "Twelfth Five-Year" Plan for Science and Technology Support (2012BAI37B03) and the Hundred Talents Program of Chinese Academy of Sciences.

Yingying Xing, Qiaoyun Chu, Run Feng, Wei Wang, Lixin Liu, Zhongbing Lu declare that they have no conflicts of interest. This article does not contain any studies with human or animal subjects performed by any of the author.

Yingying Xing ${ }^{1}$, Qiaoyun $\mathrm{Chu}^{1,3}$, Run Feng ${ }^{1}$, Wei Wang ${ }^{4}$, Lixin Liu ${ }^{1,2 \bowtie}$, Zhongbing Lu ${ }^{1 凶}$

${ }^{1}$ College of Life Sciences, University of Chinese Academy of Science, Beijing 100049, China

${ }^{2}$ Key Laboratory for Polymeric Composite and Functional Materials of Ministry of Education, School of Chemistry and Chemical Engineering, Sun Yat-Sen University, Guangzhou 510275, China

${ }^{3}$ School of Medical Science, Edith Cowan University, Joondalup, WA 6027, Australia

4 Department of Biochemistry and Molecular Biology, Capital Medical University, Beijing 10069, China

$\bowtie$ Correspondence: liulixin@mail.sysu.edu.cn (L. Liu), luzhongbing@ucas.ac.cn (Z. Lu)

\section{OPEN ACCESS}

This article is distributed under the terms of the Creative Commons Attribution 4.0 International License (http://creativecommons.org/ licenses/by/4.0/), which permits unrestricted use, distribution, and reproduction in any medium, provided you give appropriate credit to the original author(s) and the source, provide a link to the Creative Commons license, and indicate if changes were made.

\section{REFERENCES}

Acar M, Jafar-Nejad H, Takeuchi H, Rajan A, Ibrani D, Rana NA, Pan $\mathrm{H}$, Haltiwanger RS, Bellen HJ (2008) Rumi is a CAP10 domain glycosyltransferase that modifies Notch and is required for Notch signaling. Cell 132:247-258

Chu Q, Liu L, Wang W (2013) Overexpression of hCLP46 enhances Notch activation and regulates cell proliferation in a cell typedependent manner. Cell Prolif 46:254-262

Datto MB, Frederick JP, Pan L, Borton AJ, Zhuang Y, Wang XF (1999) Targeted disruption of Smad3 reveals an essential role in transforming growth factor beta-mediated signal transduction. Mol Cell Biol 19:2495-2504

Fernandez-Valdivia R, Takeuchi H, Samarghandi A, Lopez M, Leonardi J, Haltiwanger RS, Jafar-Nejad H (2011) Regulation of mammalian Notch signaling and embryonic development by the protein O-glucosyltransferase Rumi. Development 138:19251934

Guo X, Ramirez A, Waddell DS, Li Z, Liu X, Wang XF (2008) Axin and GSK3- control Smad3 protein stability and modulate TGFsignaling. Genes Dev 22:106-120

Inoue Y, Kitagawa M, Onozaki K, Hayashi H (2004) Contribution of the constitutive and inducible degradation of Smad3 by the ubiquitin-proteasome pathway to transforming growth factor-beta signaling. J Interferon Cytokine Res 24:43-54

Ma W, Du J, Chu Q, Wang Y, Liu L, Song M, Wang W (2011) hCLP46 regulates U937 cell proliferation via Notch signaling pathway. Biochem Biophys Res Commun 408:84-88

Teng Y, Liu Q, Ma J, Liu F, Han Z, Wang Y, Wang W (2006) Cloning, expression and characterization of a novel human CAP10-like gene hCLP46 from CD34(+) stem/progenitor cells. Gene 371:715

Wang Y, Chang N, Zhang T, Liu H, Ma W, Chu Q, Lai Q, Liu L, Wang W (2010) Overexpression of human CAP10-like protein 46 KD in T-acute lymphoblastic leukemia and acute myelogenous leukemia. Genet Test Mol Biomark 14:127-133

Wildey GM, Patil S, Howe PH (2003) Smad3 potentiates transforming growth factor beta (TGFbeta)-induced apoptosis and expression of the BH3-only protein Bim in WEHI 231 B lymphocytes. J Biol Chem 278:18069-18077

Xin H, Xu X, Li L, Ning H, Rong Y, Shang Y, Wang Y, Fu XY, Chang Z (2005) CHIP controls the sensitivity of transforming growth factorbeta signaling by modulating the basal level of Smad3 through ubiquitin-mediated degradation. J Biol Chem 280:20842-20850

Yang X, Letterio JJ, Lechleider RJ, Chen L, Hayman R, Gu H, Roberts AB, Deng C (1999) Targeted disruption of SMAD3 results in impaired mucosal immunity and diminished $T$ cell responsiveness to TGF-beta. EMBO J 18:1280-1291

Zhang J, Zhang X, Xie F, Zhang Z, van Dam H, Zhang L, Zhou F (2014) The regulation of TGF-beta/SMAD signaling by protein deubiquitination. Protein Cell 5:503-517
Yingying Xing and Qiaoyun Chu have contributed equally to this work.

Electronic supplementary material The online version of this article (doi:10.1007/s13238-015-0174-0) contains supplementary material, which is available to authorized users. 